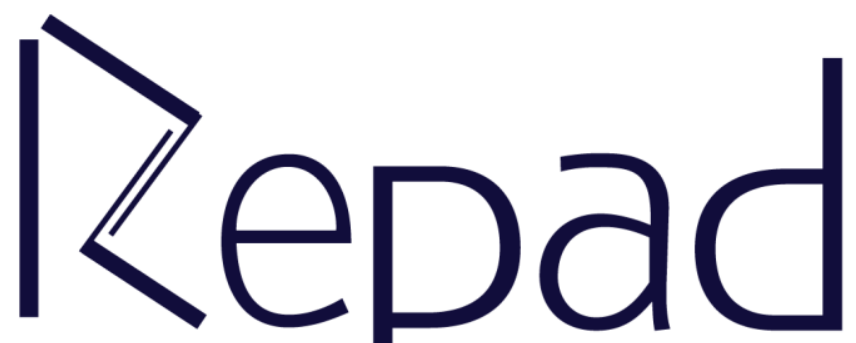

Revista Estudos e

Pesquisas em Administração 


\title{
A PARCERIA PÚBLICO PRIVADA - PPP: Uma fonte alternativa do crescimento econômico no estado de Minas Gerais?
}

\author{
Ricardo da Costa Nunes \\ rcrdnns11@gmail.com \\ https://orcid.org/0000-0002-0500-6300 \\ Universidade de Brasília \\ Brasília, Distrito Federal, Brasil \\ Selene Peres Peres Nunes \\ https://orcid.org/0000-0002-1575-3481 \\ Subsecretária do Tesouro Estadual de Goiás \\ Goiânia, Goiás, Brasil
}

\section{RESUMO}

O Estado de Minas Gerais não possui poupança para financiar despesas demandadas pela população e investimentos públicos. Esse é o motivo da busca nos recursos das Parcerias Público-Privadas (PPPs) para financiar o crescimento econômico sem comprometer o ajuste fiscal. As PPPs foram apresentadas como um instrumento capaz de alavancar o crescimento econômico em países sem recursos para financiar gastos públicos, complementando a poupança pública. Tal proposição é negada pela teoria da Escolha Pública, que afirma que os políticos estão sujeitos a grupos de interesse. O objetivo deste artigo é verificar se as PPPs contribuem para o ajuste das contas públicas e, consequentemente, para o financiamento do crescimento econômico em Minas Gerais à luz da teoria da Escolha Pública. A análise é baseada no método dedutivo e confronta as ações governamentais com o comportamento previsto pela teoria da Escolha Pública e avança na compreensão e previsão do impacto das PPPs nas contas públicas. A análise das contas públicas de Minas Gerais evidencia uma expansão dos déficits da previdência social e das despesas com pessoal, que consomem eventuais ganhos fiscais resultantes das PPPs.

Palavras-chave: Parceria Público Privada (PPP), Investimento Público, Setor Privado.

\section{THE PRIVATE PUBLIC PARTNERSHIP: An alternative source of economic growth in the state of Minas Gerais?}

\begin{abstract}
The State of Minas Gerais has no savings to finance expenses demanded by the population and public investments. This is the reason for seeking in the Public-Private Partnerships (PPPs) resources to finance economic growth without jeopardizing the fiscal adjustment. PPPs have been presented as an instrument capable of leveraging economic growth in countries without resources to finance public spending by complementing public savings. Such proposition is denied by the Public Choice theory, which stated that politicians are subject to interest groups. The purpose of this paper is to verify if PPPs contribute to public accounts adjustment and, consequently, to the financing of the economic growth in Minas Gerais in light of the Public Choice theory. The analysis is based on the deductive method and confronts governmental actions with the behavior foreseen by the
\end{abstract}


Public Choice theory and to advance in understanding and predicting the impact of PPPs on public accounts. The analysis of Minas Gerais' public accounts evidences an expansion of social security deficits and personnel expenditures, which consume eventual fiscal gains resulting from the PPPs.

Keywords: Public-Private partnership (PPP), Public Investments, Private Sector.

Submetido: 14/11/2019

Aceito: 30/01/2020

Publicado: 31/01/2020

\section{INTRODUÇÃO}

A implementação das Parcerias Público-Privadas (PPPs) visa eliminar restrições de financiamento público com a realização de obras de infraestrutura pelo setor privado e assim aumentar o volume de investimentos e o crescimento econômico, como apontado por Pasin e Borges (2003). Outro resultado esperado do emprego das PPPs seria o de melhorar a eficiência na gestão de empreendimentos públicos. A norma criadora e regulamentadora das PPPs, o PL $\mathrm{n}^{\circ}$ 2.546/2003, posteriormente convertido na Lei $\mathrm{n}^{\circ}$ 11.079/2004, considerou as PPPs como um instrumento fundamental para a promoção do crescimento econômico e do aumento da eficiência da gestão pública devido a maior produtividade da administração privada como apresentado na Exposição de Motivos Interministerial ( EMI) $n^{\circ}$ 355-03/MP/MF, Brasil (2003).

Os estudos sobre as PPPs se resumem ao seu formato para que sejam bemsucedidas em fomentar o fornecimento de bens públicos sem contemplar a situação das contas públicas dos entes e a determinação dos governos de alcançarem crescimento econômico.

Este estudo assume a hipótese de que o alcance do crescimento com a adoção das PPPs depende de que a política econômica do Ente esteja orientada para o crescimento econômico e a burocracia estatal subjugada à política do Estado. Esta seria a contribuição inovadora deste trabalho.

Em vista do exposto, o objetivo deste trabalho é analisar o papel que as Parcerias Público-Privadas (PPPs) podem ter no financiamento do crescimento econômico em Minas Gerais. Assim, para o alcance do objetivo deste trabalho, realiza-se um breve diagnóstico da situação fiscal do Estado de Minas Gerais no período 1996-2016, enfatizando os dois últimos anos, identificando as causas desse quadro, bem como as variáveis que deverão merecer maior atenção por parte dos gestores públicos, seja por serem parte do desenvolvimento econômico almejado, seja pelas implicações legais relacionadas a um descumprimento da Lei de Responsabilidade Fiscal - LRF e das demais normas orçamentárias. Trata-se de uma discussão teórica e qualitativa que utiliza como base os autores da Escola das Escolhas Públicas e a aplicação da econometria.

O trabalho está dividido em 3 capítulos, além da introdução e dos comentários finais. No capítulo enumerado como segundo é apresentada a Situação fiscal do Estado de Minas Gerais no período 2014-2016. No terceiro capítulo, apresenta o Estado de Minas, como interventor na economia e gastador em busca do financiamento privado para fomentar o crescimento econômico. O quarto capítulo descreve a metodologia para a 
análise, com base em indicadores construídos, despesa com pessoal sobre arrecadação com ICMS, dívida fundada sobre o PIB estadual e serviço da dívida sobre PIB estadual.

\section{SITUAÇÃO FISCAL DO ESTADO DE MINAS GERAIS ${ }^{1}$}

O Produto Interno Bruto a preços de mercado correntes do Estado de Minas Gerais foi estimado em $\mathrm{R} \$ 516,6$ bilhões em 2014, o que representava 8,9\% do PIB nacional, segundo a Fundação João Pinheiro ${ }^{2}$. Apesar da dimensão econômica e das potencialidades do Estado, sua situação fiscal pode ser considerada frágil, com problemas que vão desde a dificuldade em honrar dívidas até atrasos no pagamento do funcionalismo, embora reconhecendo que a dificuldade é extensiva a outros entes da federação.

O Estado de Minas Gerais possuáa, de acordo com o Balanço do Setor Público Nacional (BSPN) de $2015^{3}$, a segunda maior receita estadual do País, ou 9,72\% das receitas estaduais. O Estado, situa-se no grupo dos estados ricos (São Paulo, Rio de Janeiro, Minas Gerais e Rio Grande do Sul), responsáveis por mais da metade da receita estadual do País.

Todavia, no período 2014-2016, as receitas correntes, mantiveram-se praticamente constantes em termos nominais em todo o período analisado, o que quer dizer que, considerando a inflação, houve queda real. Neste mesmo período, merece nota o fato de que as operações de crédito novas, que eram modestas em 2014-2015 cresceram atingindo $\mathrm{R} \$ 1,1$ bilhão em 2016, o que pode comprometer o ajuste do Estado já em situação fiscal difícil.

Em vista do exposto, preocupa que o montante da receita tributária esteja aquém do seu potencial quando se compara aos outros três Estados ricos. A este respeito, segundo estimativas da Lei de Diretrizes Orçamentárias - LDO, o Estado teria perdido cerca de $\mathrm{R} \$ 5,273$ bilhões em 2016, devido à renúncia de receita. Uma possível explicação para uma menor arrecadação seria o atendimento do Governo a reinvindicações de grupos privados, como apontado por Monteiro (2007) e Buchanan e Congleton (1998). A troca de favores entre políticos e grupos de interesse que permite a edição de normas prevendo renúncia de receitas é denominado de logrolling, como esclarecido por Falcão e Neiva (2017). A benevolência presente nas normas concedentes de benefícios fiscal é denominada de dilema do samaritano por Buchanan (1972) porque o doador concede o benefício para o beneficiado que usa os recursos de forma sub-ótima, como exposto por Nazareth e Lírio (2016). Na ótica da escola das escolhas pública, como apresentado por Tullock (2006), a finalidade da concessão dos incentivos fiscais, que acabam por reduzir receitas, visa a obtenção de apoio dos grupos favorecidos aos governantes.

A adoção de práticas de contabilidade criativa também pode ser empregada pelos governantes no esforço de reeleição, como apontado Silva (2018). Nos anos recentes, a pouca transparência das Contas públicas do Estado de MG manifesta-se com impropriedades na contabilização decorrente da classificação por funções. Evidencia-se a imprecisão da contabilidade com a despesa com previdência de $\mathrm{R} \$ 13$ bilhões, que não

\footnotetext{
1 Este trabalho não expressa nem reflete a opinião de nenhum órgão do Governo Federal. Todas as informações utilizadas na sua elaboração são públicas e devem ser objeto de ampla divulgação, inclusive por meio eletrônico, graças às disposições da LRF, art. 48 e 51.

2 Ver: http://www.fjp.mg.gov.br/index.php/produtos-e-servicos1/2745-produto-interno-bruto-de-minasgerais-pib-

3 Disponível na página da Secretaria do Tesouro Nacional http://www.tesouro.fazenda.gov.br/balanco-dosetor-publico-nacional-bspn-. O Balanço do Setor Público Nacional (BSPN) é a consolidação dos balanços anuais segundo auto-declaração dos governos de Estados e Municípios brasileiros.
} 
parece ser compatível com outros dados do Demonstrativo de Receitas e Despesas Previdenciárias, que indica despesas da ordem de R\$19,2 bilhões. A ausência de transparência seria explicada por Cruz (2017) para quem o gestor público procura não disponibilizar informações fidedignas para obter maior aceitação com o aumento de eleitores mal informados.

Constata-se, no entanto, que a contabilidade criativa implementada no Estado não permitiu criar recursos para pagamento, por exemplo, do décimo-terceiro salário do funcionalismo e, mais recentemente, do próprio salário, muitas vezes realizado com atraso. Com a queda de arrecadação a partir de 2013, tornou-se impossível honrar com os pagamentos da folha com pontualidade.

O exame das contas do Estado de MG mostra que sequer o caminho da prudência determinado pela LRF foi seguido, agravando a situação econômica. Foram concedidos sucessivos aumentos ao funcionalismo em 1999, 2000, 2001, etc. Como a opção adotada foi a crítica à LRF, aumentando-se os desajustes ao invés de reduzi-los, caberia ao Tribunal de Contas cobrar multa de 30\% dos vencimentos anuais do Chefe de Poder, por não haver adotado as medidas necessárias ao ajuste pelo qual é responsável. No entanto, o próprio TCE-MG adotou as Instruções Normativas $n^{\circ} 1$ e 5/2001, que autorizaram a exclusão de inativos e pensionistas, permitindo reduzir a relação despesas de pessoal/receita corrente líquida. A partir de então, segundo o TCE-MG, o Estado vem adotando duas metodologias: uma de acordo com o Manual de Demonstrativos Fiscais MDF, editado pela Secretaria do Tesouro Nacional - STN e outra de acordo com as Instruções do TCE-MG. Destaque-se que a mesma dicotomia ocorre no cálculo dos limites da despesa com pessoal em todos os Poderes do Estado.

Já na análise das Contas de 2014, o Relatório Técnico do TCE-MG afirmava que o grupo de despesa a apresentar o saldo mais relevante nos Restos a Pagar ProcessadosRPP é o de Pessoal e Encargos Sociais, com R\$ 1,716 bilhões, representando 49,24\% do total de RPP, pertencendo ao Executivo o montante de R\$1,631 bilhão, equivalente a 95,08\% do total desse grupo. Assim, o saldo da conta Despesas Correntes - Pessoal e Encargos Sociais - 3.3.1.00.00.00 - teria registrado, em dezembro/2014, R\$ 36,279 bilhões de despesas realizadas a esse título, concluindo-se que $4,73 \%$ foram inscritas em RPP, não estando consideradas, nesse montante, as empresas estatais dependentes. Não parece razoável que despesas com pessoal sejam inscritas em RPP, pois não deveria haver atrasos dessa natureza.

De acordo com a STN ${ }^{4}$, em 2015, a diferença entre a relação Despesa Total com Pessoal/Receita Corrente Líquida declarada pelo Estado e a aferida pelos técnicos da STN, no âmbito do Programa de Reestruturação e Ajuste Fiscal - PAF é da ordem de $20,67 \%$. A relação de $78 \%$ seria a maior verificada no País.

O Estado teria também a maior participação das despesas com pessoal nas despesas primárias do País, o que torna difícil gerar resultados primários e o segundo maior crescimento real das Despesas com Pessoal entre 2009 e 2015. A evolução das despesas com pessoal no triênio em análise demonstra o agravamento da situação.

Ainda que se defenda a inclusão de inativos e pensionistas no cálculo da despesa de pessoal, é mister reconhecer que a previdência se afigura como o principal problema das finanças públicas, indicando a necessidade de medidas urgentes para reverter os números atuais. No Estado, o déficit do RPPS já atingiu R\$ 14,8 bilhões em 2016. A despesa com pessoal elevada indica que futuramente o problema poderá tornar-se ainda

\footnotetext{
${ }^{4}$ Boletim das Finanças Públicas dos Entes Subnacionais, 2016.
} 
mais grave, na medida em que os ativos de hoje serão os inativos de amanhã e os inativos de hoje serão os pensionistas de amanhã. Assim, o que mais preocupa não é o nível atual, mas principalmente a possibilidade de desequilíbrios futuros.

A LRF estabelece que deverá ser buscado o equilíbrio financeiro e atuarial da previdência. Contudo, a utilização de aportes para cobertura de déficit atuarial para pagar inativos e pensionistas quase que imediatamente depois indica que, no futuro, faltarão recursos. Além disso, conforme apontou o TCE-MG, em 2014, a previsão da reserva orçamentária, no valor inicial de $\mathrm{R} \$ 1.110 .492 .329,00$, foi utilizada como fonte para a abertura de crédito suplementar para pagamento de benefícios previdenciários, por meio do Decreto Estadual NE 29, de 21/1/2014.

A conduta administrativa do governo de Minas Gerais é contrária a idealmente esperada por Merton (1978). Para o citado autor, as ações da burocracia do Governo de Minas deveriam atender as normas estabelecidas no País e no Estado.

Na corrente da burocracia da Escola das Escolhas Pública, a despesa com pessoal crescente e o consequente aumento da dívida pública é explicada por reivindicações corporativistas atendidas por políticos desejosos de manter seus cargos, como apontado por Marlow e Orzechowsky (1996) e Borcherding, Bush e Spann (1977). Trata-se de uma barganha de favores entre eleitores e políticos. Há a aprovação de projetos de leis que, ainda que onere toda a sociedade, gera benefícios para um grupo de eleitores comprometidos com a eleição do parlamentar, como apontado por Falcão e Neiva (2016).

Os autores da Escola da Escolha Pública mostraram que o benefício privado dos formuladores de política econômica que procuravam perpetuar-se no poder pode estar por trás das iniciativas de expansão da despesa com pessoal. Em todo o período analisado, foi crescente o pagamento de encargos com pessoal. $\mathrm{O}$ crescente gasto com pessoal revela $\mathrm{o}$ atendimento corporativista dos servidores atuando em sentido contrário ao ajuste fiscal.

De acordo com Buchanam (1967), os servidores poderiam atender as exigências dos funcionários superiores em troca de benefícios profissionais. A própria eleição de parlamentares comprometidos com a defesa de interesses corporativos de servidores está previsto em Buchanam. Tem-se assim que o principal mérito da burocracia de controle técnico previsto, que no caso se traduziria em atendimento de normas que visam a disciplina fiscal, em Merton, acaba deixando de ser eficaz.

A situação fiscal do Estado de Minas Gerais é muito frágil, qualquer que seja a variável analisada. Mesmo que a economia volte a crescer, a situação da previdência, o nível de comprometimento com despesas com pessoal, o descumprimento do limite da dívida e o nível das obrigações financeiras não cobertas por disponibilidade de caixa são preocupantes. Em outras palavras, a questão fiscal não será facilmente equacionada. Mesmo que ocorra o refinanciamento de dívidas junto à União, há sempre o risco de que a folga fiscal gere acomodação ou estímulo ao aumento das despesas com pessoal. Os problemas estruturais, tanto na receita como na despesa, precisam ser superados para que o ajuste seja possível.

A menor preocupação com a disciplina fiscal dos entes subnacionais é assinalada em Nunes e Nunes (2000). Em 2016, a situação fiscal do Estado foi atenuada pela edição da Lei Complementar $n^{\circ}$ 156/2016. A norma determinou a suspensão das dívidas dos estados perante a União. No entanto, a exigência de suspenção dos reajustes salarias para os servidores por dois anos foi retirada.

Ressalte-se que a falta de transparências nas contas do Estado e da realização de contabilidade criativa estão em coadunância com os pressupostos da Teoria das Escolhas Públicas. O alcance dos interesses próprios dos gestores públicos em detrimento dos 
eleitores na gestão pública está previsto em Tullock (2006), o qual é possível com a reeleição a despeito de uma má gestão se não há transparência dos gastos públicos.

\title{
3. O PARADOXO DE O ESTADO DE MINAS GERAIS (MG) INTERVENTOR E GASTADOR EM BUSCA DO FINANCIAMENTO PRIVADO
}

A Constituição Federal admite o direito à propriedade condicionado à uma função social que, por sua vez, de setores da economia em que é necessária a atuação do Estado. Nestas áreas, a participação do Estado é admitida por lei para a regulação e até mesmo para a produção, sempre para atender o interesse coletivo. Este aspecto é destacado por Di Pietro (2005, p. 99) para quem "a lei atribui (competência) ao Estado para que a exerça diretamente ou por meio de seus delegados, com o objetivo de satisfazer concretamente às necessidades coletivas, sob regime jurídico total ou parcialmente público." Esta perspectiva foi prevista no parágrafo $4^{\circ}$ do art. 173 da Constituição, que determina que "A lei reprimirá o abuso do poder econômico que vise à dominação dos mercados, à eliminação da concorrência e ao aumento arbitrário dos lucros”. A Carta Magna prevê ainda que a eficiência do gasto público deve ser buscada em atendimento ao princípio constitucional:

\begin{abstract}
que impõe à administração pública direta e indireta e a seus agentes a persecução do bem comum, por meio do exercício de suas competências de forma imparcial, neutra, transparente, participativa, eficaz, sem burocracia e sempre em busca da qualidade, primando pela adoção dos critérios legais e morais necessários para melhor utilização possível dos recursos públicos, de maneira a evitarem-se desperdícios e garantir-se maior rentabilidade social (MORAES, 1999, p. 30).
\end{abstract}

O Estado de MG, como demais entes subnacionais brasileiros, é claramente interventor para atender aos ditames da justiça social para promover direitos individuais e sociais e em parte porque há setores da economia em que é necessária a atuação do Estado, não admitindo o Laissez-Faire, como estabelecido na Carta Magna. Essa foi a observação que delineou a doutrina da intervenção estatal sacralizada, em 1959, no Bad Gottesberg Program do Partido Social Democrata Alemão: "os mercados quando possível, o Estado quando necessário”, ver Przeworski (1996, p. 117).

Dessa forma, ao que se depreende, é que os entes federativos, a partir de 1988, com promulgação da Constituição Federal, paradoxa e democraticamente, convivem hoje com um sistema misto, vale dizer, com as duas experiências de Estado, o "Estado de Bem Estar Social", defendido por Keynes e, ao mesmo tempo, com o "Estado Neoliberal", sustentado por Friedman e Friedman (1977), rumando assim, com as suas características próprias.

Nesta nova ordem econômica estabelecida na Constituição Federal de 1988, coube ao Estado, a responsabilidade de ser o agente normativo e regulador, exercendo as funções de fiscalização, notadamente por intermédio de Agências Executivas e Reguladoras, todavia, incentivando o regime de livre competição ou pelo mercado livre.

A suposta inesgotabilidade dos recursos públicos passou a ser questionada, diante da ineficiência, direta ou indireta do Estado enquanto prestador de serviços públicos. $\mathrm{O}$ fato de que o Estado não tenha recursos para financiar obras para alavancar o crescimento econômico levou a que se buscasse nas PPPs uma via alternativa para fomentar o crescimento no país. A capacidade do Estado em financiar obras para alavancar o crescimento econômico está em parte obstaculizada. Esses fatos levaram o Poder Público 
a buscar novos recursos para manter seus serviços e a delegação contratual desses serviços a particulares. Emerge a Parceria Público Privada - PPP como fonte alternativa de financiamento do crescimento econômico. Assim, origem da concessão e permissão do serviço público remete à crise do Estado interventor.

Há uma elevada dívida pública que encarece o financiamento de novos investimentos. Há ainda exigência de equilíbrio das finanças públicas por meio da LRF. Necessidade de se buscar superávit primário para o abatimento de dívida pública e poucos recursos orçamentários livres no orçamento devido a elevada vinculação de receita a despesas com educação, saúde e seguridade social. Temos o esgotamento da capacidade de investir do Estado. Ademais, a constatação da ineficiência da intervenção governamental reforçou o entendimento de que as PPPs são sim uma terceira via para o financiamento do crescimento econômico.

Neste quadro, sobressai a crença de que crescimento da economia mineira depende, em parte, de fontes alternativas de financiamento e do afrouxamento de restrições, regulamentos e burocracia que o Estado impõe à sua sociedade, como previsto na Lei que criou as PPPs.

Há ainda o diagnóstico da Escola de Escolhas Públicas de que quanto mais o Estado intervém na economia e permite o aumento de dívida pública, maior fica a necessidade de se recorrer à substituição da atividade pública pela privada. As PPPs têm sido uma forma recorrente de substituição de ação pública pela privada. A constatação da relação entre o aumento da intervenção pública e o crescimento do déficit público, que acaba por incrementar a dívida pública foi realizada por Roubini (1989) para o caso da Itália entre os anos 1960 e 1980. Também, para Landau (1985), a fonte de ineficiência da economia é a propriedade pública, existindo, para a autora, uma relação inversa entre a participação do Estado na economia e a produtividade.

Assim, as PPPs são vistas como necessárias para a realização de investimentos para impulsionar a economia. Tem-se assim que as PPPs são justificadas pelos fatores de natureza fiscal e pela expectativa de que as capacidades gerenciais e financeiras do setor privado resultem em aumentos de eficiência na economia do Estado.

Há, no entanto, de se reconhecer que o sucesso das PPPs para alavancar o crescimento econômico do País depende de que as empresas contratadas pelo serviço público sejam eficientes. Brey (2013) e Boubakri, Cosset e Saffar (2008) afirmam que as empresas públicas são ineficientes. Para Friedman e Friedman (1977), a empresa privada é mais produtiva do que a empresa pública. IMF (2004) divulgam que para aumentar a eficiência na economia a entrada de capital e gerenciamento privados podem contribuir para o aumento da eficiência. Mais recentemente, tem-se a proposição da Nova Gestão Pública (NGP) que reivindica que a burocracia pública seja eficiente, como preconizada por Weber (1994), como uma modalidade de organização com adequação dos meios aos objetivos desejados, a fim de alcançar a máxima eficiência.

Contribui para a contratação de empresas eficientes, um ambiente regulatório sólido. Contabilmente, já há orientação aos concessionários por intermédio da interpretação técnica ICPC 01, que esclarece como contabilizar as atividades oriundas das PPPs. O tratamento a ser seguido pelas concedentes está previsto na NBC TSP 05.

Relativamente aos aspectos jurídicos, Wald (2005) aponta que as normas que tratem das PPPs devem ser bem delineadas e que proporcionem segurança ao empreendedor privado. A adequada legislação pode favorecer as contratações de PPPs, na medida em que desfavorecem ações oportunistas e contratos mal elaborados, ou na denominação de Sarmento e Renneboog (2017), contratos incompletos. 
É indiscutível que o intuito de dirimir incerteza nos contratos de PPPs tenha motivado a legislação inglesa de retirar o direito de imperium nos contratos de PPPs. Tal medida contribui para que haja um entendimento comum entre o setor privado e público sobre os contratos de PPPs, restringindo a judicialização e proporcionando segurança jurídica para os atos econômicos.

Assim, as disputas judiciais em torno das PPPs podem deixar de obstaculizar o financiamento privado de empreendimentos públicos. A redução de litígios pode também contribuir para o aumento de participantes nos leilões de PPPs, contribuindo para que os estados consigam lances mais rentáveis.

Neste contexto, é de suma importância a elaboração de editais, contemplando distintas situações econômicas e estabelecendo nos contratos controles de resultado adequados que sejam capazes de apresentar solução as questões envolvendo as PPPs. A matéria sobre concessões na modalidade de PPP está inserida num meio jurídico de fog of wright (nevoeiro do direito) que é constituída de grande número de conflitos de diferentes matizes (direito, políticos, sociais, econômicos, culturais, éticos, trabalhistas, etc.).

Eventuais prejuízos econômicos com emprego de PPPs podem surgir devido a elaboração de editais mal-elaborados. A título de exemplo, apresenta-se o que se sucedeu em Yogyakarta na Indonésia. Em 2002, o Prefeito de Yogyakarta decidiu realizar uma concessão na modalidade de Parceria Público Privada (PPP) para a construção e exploração de um novo terminal Rodoviário porque não havia recursos orçamentários para financiá-lo.

Ocorre que, na preparação do edital, a Prefeitura não contemplou todas as situações econômicas relevantes, como previsto na teoria Economia das Instituições, em que a implementação de políticas públicas é cerceada pela presença de assimetria de informações, oportunismo e racionalidade limitada dos agentes, como descrito em Dias (2014). O Edital se limitou aos seguintes critérios econômicos: o pagamento da concessionária à cidade, a taxa por ônibus que a concessionária iria cobrar dos operadores de ônibus para utilizar o terminal e que o novo terminal rodoviário seria exclusivo da cidade. A PTPK foi selecionada como a vencedora e assinou um contrato "construiroperar-transferir" (BOT) de trinta anos.

Em 2009, a PTPK alegou não cumprimento de cláusula contratual, por parte da Prefeitura, de preservar exclusividade da Empresa em explorar o terminal rodoviário. Ainda de acordo com a PTPK, a concorrência dos terminais concorrentes seria responsável pela queda de rentabilidade do novo terminal rodoviário, inviabilizando a continuidade dos serviços e o investimento em outros itens previstos no Edital. Assim, a PTKP solicitou o cancelamento do contrato de concessão e o reembolso pelo valor do negócio do novo terminal.

Tem-se assim que, a má elaboração do Edital de Concessão pelo Município de Yogyakarta pode trazer prejuízos ao Ente público. Portugal é outro exemplo de resultado desfavorável com as PPPs. O País ibérico acabou desembolsando mais com as PPPs do que se tivesse realizado investimentos diretos. Esse mau uso decorreu das condições estabelecidas nos Editais e a desaceleração da economia que deprimiu a demanda, o que resultou em queda de receitas das empresas parceiras e a assunção pelo Governo dos prejuízos.

Em vistas dos possíveis prejuízos a serem assumidos pela Municipalidade, aventou-se a possibilidade de uma disputa judicial com a Empresa. No Brasil, a Municipalidade poderia recorrer ao instrumento jus imperi, o que favoreceria a iniciativa 
pública. No entanto, se o Juiz considerasse as prerrogativas da Municipalidade como Administração Pública, seria admitida a prerrogativa de alterar unilateralmente o contrato. Trata-se do princípio "jus variandi", que faz com que o contratado esteja obrigado a aceitar a alteração unilateral, quando garantido o equilíbrio econômicofinanceiro do contrato.

No entanto, uma suposta e improvável vitória prejudicaria severamente os princípios da livre-iniciativa e da livre concorrência. Acresce-se que de acordo com o ordenamento jurídico, o contrato faz lei entre as partes: pacta sunt servanda. Assim, o contrato celebrado somente pode ser modificado pelo consenso das partes. Esse princípio denominado de força vinculante não admite exceções para o seu cumprimento.

Assim, para que o país possa melhorar o seu grau de institucionalização, há necessidade de que as leis vigentes possam ser cumpridas, como previsto no texto legal. A necessidade de ajustes do Direito, para propiciar um ambiente favorável à realização de investimentos, como a ocorrida na Grã-Bretanha, já tinha sido preconizada por Weber (1994). Para compreender a situação do Estado é preciso se ater que esta é desenhada a partir das Leis cuja eficácia depende do desenvolvimento institucional do País. É por intermédio das normas que serão implementados os instrumentos fiscais, a carga tributária e o fornecimento de bens públicos. Tal proposição é corroborada pelo trabalho de Alesina (1996) e Arraes e Teles (2000) para quem os elementos institucionais explicam as diferentes taxas de crescimento entre as economias. Também Cardoso, Correa e Lima (2009, p. 82) apontam como o desenvolvimento do grau de institucionalização do País como um elemento necessário ao aumento da taxa de crescimento econômico, indicando que "a Irlanda já havia desenvolvido alguns dos pré-requisitos para o crescimento rápido (...) efetividade das instituições relacionadas ao estabelecimento de leis".

Necessário destacar que eventuais ganhos fiscais com as PPPs poderiam ser perdidos com elevação de gastos em outras áreas públicas. Assim, é preciso que o Estado busque uma disciplina fiscal em toda a sua administração pública em que qualquer aumento de despesa pública deve ser pautado pela responsabilidade fiscal, como previsto na Lei Complementar $n^{\circ} 101 / 2000$ e que haja toda transparência e fidedignidade dos dados das contas públicas, como previsto na citada Norma, para que a sociedade possa acompanhar a situação financeira e os gastos públicos.

O caso do Estado de Minas Gerais foi preocupante no período entre 2014 e 2016 porque pode ter flexibilizado ainda mais a disciplina fiscal. Há inconsistência entre as informações da Receita Tributária do Balanço Orçamentário e do Demonstrativo da Receita Corrente Líquida da ordem de R $\$ 6$ bilhões em 2014 e 2015, aumentando para R \$ 6,6 bilhões em 2016. No Balanço Orçamentário, as receitas tributárias somam R \$ 46,2 bilhões, enquanto no Demonstrativo da Receita Corrente Líquida somam R \$ 52,9 bilhões em 2016. A receita arrecadada divulgada pela Secretaria de Fazenda do Estado apresenta números também diferentes.

O Demonstrativo do Estado não trouxe nem a compensação das renúncias nos moldes estabelecidos no Manual de Demonstrativos Fiscais, nem a análise dos critérios estabelecidos para as renúncias. Além disso, embora a LRF determine a inclusão de benefícios financeiros e creditícios no Demonstrativo, não foram incluídos subsídios sob a forma de empréstimos e financiamentos relativos aos Fundos de Desenvolvimento gerenciados pelo Banco de Desenvolvimento de Minas Gerais - BDMG. Também deveriam estar incluídos subsídios referentes à conta Concessão de Financiamentos Habitacionais, com saldo de $\mathrm{R} \$ 991,225$ milhões, em sua maioria referentes ao Fundo de 
Apoio Habitacional aos Militares do Estado de Minas Gerais - Fahmemg e o ao Fundo de Habitação.

De acordo com o Tribunal de Contas do Estado de Minas Gerais - TCE-MG5 a partir de setembro de 2012, o Estado vem deduzindo, do somatório das Receitas Tributárias e de Outras Receitas Correntes, valores referentes à Cessão de Direitos Creditórios a Minas Gerais Participações S.A - MGI. Souyri ${ }^{6}$ (1977, p. 42) descreve tal situação como comum para muitos Entes quando afirma que "o estado, enfim, sustenta mais diretamente os lucros generalizando a política de subvenções às grandes firmas e praticando de uma maneira a tornar-se permanente".

Explorar mais a base de arrecadação do ICMS significa reduzir a renúncia de receita e intensificar os esforços de fiscalização e cobrança de tributos, tal como preconiza a LRF, ao determinar que todos devem instituir, prever e arrecadar os tributos de sua competência. O intuito deste dispositivo da LRF é o de mitigar a tendência dos entes de realizarem menor cobrança de tributos e assim preservarem índices de popularidade, como previsto nos modelos de interações político-econômicas, como em Pissarides (1980). Assume-se que os índices de popularidade crescem com o crescimento da renda disponível possível com a renúncia fiscal.

De acordo com o Princípio da eficiência, o Governo deve produzir mais a igual ou a menor custo, o que permite uma melhor utilização dos recursos públicos e garante também uma maior rentabilidade social. Sendo que o princípio da eficiência é um dos alicerces que deve nortear todas normas e condutas produzidas na legislação brasileira, orientando o gestor público na administração pública, em atendimento ao princípio da supremacia da CF. Pelo princípio da máxima efetividade da norma constitucional voltadas ao direito público é de se esperar que os gestores públicos interpretem os dispositivos mencionados de modo a "otimizar-lhes a eficácia, sem alterar o seu conteúdo", como exposto por Branco, Coelho e Mendes (2008, p. 118). Sendo que o texto constitucional ainda prevê expressamente sanção aos atos contrários à moralidade administrativa.

Aumentos de despesas superiores aos das receitas verificados no período 20142016 se traduzem como redução de eficiência porque são produções a custos crescentes. Apesar da crise econômica que gerou a queda da arrecadação de receitas, as despesas correntes continuaram crescendo. O comportamento das despesas correntes é praticamente determinado por Despesas com Pessoal e Encargos Sociais e Outras Despesas Correntes que desconsiderando as intra orçamentárias, representam, respectivamente, $61,21 \%$ e $32,73 \%$ do total das despesas. A tentativa de ajustar as despesas às receitas ocorreu nas Despesas de Capital, basicamente em Investimentos e Inversões Financeiras. Essa não é a melhor forma de fazer ajuste fiscal se considerarmos que o crescimento econômico poderia se alavancado por investimentos. No entanto, em 2016, essa rubrica representou pouco mais de $2 \%$ da despesa, um valor insignificante face às potencialidades e necessidades do Estado.

Também contribui para a redução da eficiência os gastos com Legislativo e Judiciário serem mais de seis vezes superiores a tudo que se gasta com Transporte $(1,13 \%)$. Algumas rubricas socialmente importantes como Habitação e Saneamento

\footnotetext{
${ }^{5}$ Relatório sobre a Macrogestão e Contas do Governo do Estado de Minas Gerais, Exercício de 2014, Tribunal de Contas do Estado de Minas Gerais, p. 123 e 178.

${ }^{6}$ Neste caso, para os autores marxistas, aplicar-se a tese marxista de que o desenvolvimento do capitalismo é acompanhado pela atuação direta do Estado, ora na manutenção e ampliação das taxas de lucro dos empresários, ora na manutenção das condições de reprodução do sistema capitalista.
} 
foram agrupadas em Outros por terem valores irrelevantes. A principal despesa refere-se a Encargos Especiais, refletindo o peso do pagamento de dívidas. $O$ efeito nefasto da despesa com pessoal nestes Poderes é previsível na corrente da burocracia da Escola das Escolhas Públicas para quem o atendimento das reivindicações corporativistas dos servidores públicos deteriora as contas públicas, como apontado por Marlow e Orzechowsky (1996) e Borcherding, Bush e Spann (1977). As reinvindicações de aumento de salários acima da produtividade contrariam o entendimento de Weber (1994) sobre burocracia como uma modalidade de organização com adequação dos meios aos objetivos desejados, a fim de alcançar a máxima eficiência.

O sucesso do papel do Estado em fazer cumprir a ordem no país, resulta no que pode ser denominado de institucionalidade. Não é por outra razão que a qualidade da infraestrutura institucional é apontada pelos economistas como um elemento importante para o crescimento. Cardoso, Correa e Lima (2009) atribuem o elevado grau de institucionalização da Irlanda como um fator que promoveu o crescimento econômico, levando o país a ser denominado de tigre celta.

As empresas privadas que fazem Parceria Público Privada (PPP) estão menos sujeitas a controle e seguem a lógica privada buscando a maximização de lucros, sendo, por isto, mais eficientes que as empresas públicas. Para Shapiro e Willig (1990), a ineficiência dos empreendimentos públicos pode decorrer do fato de os seus dirigentes muitas vezes serem nomeados por razões políticas e por isso perseguirem os seus objetivos próprios ou daqueles que os indicaram para o cargo. O Governo pode se beneficiar da maior eficiência das empresas privadas realizando serviços públicos, estabelecendo nos contratos controles de resultado adequados.

A existência de um ambiente regulatório sólido é um requisito importante para que as empresas sejam eficientes e atendam o dispositivo constitucional que exige eficiência das ações governamentais. O País com um sistema legal operante, onde há o Estado de Direito ${ }^{7}$, protegendo os direitos de propriedades, as instituições públicas e privadas tendem a ser mais rentáveis.

No entanto, de pouco adianta o ganho de receita e de aumento de eficiência com as PPPs se o Governo de MG continuar realizando déficits primários decorrentes de gasto com pessoal. Isto porque o limite dos gastos decorrentes das PPPs primeiramente não é expressivo, insuficiente para alavancar o crescimento por si. O art. 28 Lei Nacional $\mathrm{n}^{\mathbf{o}}$ 11.079/2004 estabelece o limite de 5\% da Receita Corrente Líquida (RCL) com desembolsos decorrentes de contratos de PPPs.

Com a realização dos contratos de PPPs, a empresa privada frequentemente fica incumbida pelas contratações necessárias ao empreendimento, o que reduz os custos governamentais relacionados ao acompanhamento e controle da despesa pública, das licitações, e demais atividades administrativas associadas. $\mathrm{O}$ menor gasto com administração dá ao Poder Público recursos para fomentar o crescimento econômico ou para manter gastos visando a reeleição de seus governantes.

Tem-se assim a preservação do ambiente institucional na burocracia pública com normas rígidas, hierarquia, centralização decisória e indicação política para os dirigentes governamentais, aspectos causadores de ineficiência.

Ressalte-se que, mesmo que se apresentem fatores de natureza fiscal, o principal elemento que justifica a adoção de PPP é a expectativa de que as capacidades gerenciais

7 Entende-se Estado de Direito como um sistema que enfatiza os direitos dos credores e fiscaliza rigorosamente os contratos. 
e financeiras do setor privado resultem em aumentos de eficiência nas empresas e atividades submetidas transferidas ao setor privado.

Assim, as despesas com investimentos precisam ser com frequência limitadas para encontrar espaço para os pagamentos de juros da dívida. Assim, como os títulos da dívida são hoje e foram no passado emitidos para financiar o déficit, a dívida pública é tanto consequência do processo orçamentário como parte dele no momento atual. Tal fato tende a ganhar relevância com a aceitação do teorema da equivalência de Ricardo que nos diz que o aumento da dívida equivale a um aumento de impostos o que tem por contrapartida uma queda do consumo para fazer frente ao aumento de despesa financeira, uma vez que esta dívida terá que ser paga no futuro.

Assim, foi apresentada a PPP, uma forma de concessão, em que se tem a ideia de que o empreendimento continua público, como o próprio nome informa, porque está sujeita a regulação do Estado. Os órgãos governamentais reguladores atuam para impedir o abuso do poder de monopólio pelos empresários. O projeto do governo é o de eliminar os pontos de estrangulamento econômico, dentre os quais o principal é o da infraestrutura. De qualquer forma, é importante reconhecer que a estratégia aparece como uma opção particularmente atrativa para governos constrangidos por problemas de natureza financeira e fiscal, como apresentado por Romp e De Haan (2007).

Pode assim o Partido dos Trabalhadores, governante a época, que criticava a desestatização, dar prosseguimento a transferência de empresas públicas para o setor privado incluindo, inclusive, os serviços públicos por intermédio das PPPs, com críticas minimizadas. As PPPs foram consideradas uma terceira via, uma vez que não estão relacionadas, no entendimento popular, com a visão liberal. É neste contexto que, no Brasil o projeto da parceria público-privada, foi implementado pelo Governo em 2004. Considerando Cossalter (2004), poderíamos ficar surpresos com a implementação de PPPs por partidos de esquerdas, pois tais ações públicas seriam conservadoras porque implicam na redução das despesas públicas com a transferências de atividades típicas de Estado ao setor privado. Assim, o projeto de PPP está indo além da desestatização de governos anteriores.

Nos últimos anos, o setor público, em diversos países se deparou com a necessidade econômico-administrativa de viabilizar investimentos em contexto de restrição fiscal recorrendo a PPPs. Cabe ressaltar que tal procedimento obteve grande sucesso em diversos países, como a Inglaterra, Irlanda, Portugal, Espanha e África do Sul. Sendo este um dos motivos para que o Brasil também buscasse nas PPPs uma alavanca para o crescimento econômico, situação registrada pelo Legislador e apresentada na EMI n 355/2003/MP/MF, ver Brasil 2003.

$\mathrm{Na}$ Inglaterra, da mesma forma que no Brasil para os governos federais e subnacionais, as principais assertivas que justificam a adoção das PPP foram a expectativa de melhoria nos serviços públicos baseada na crença de que as empresas privadas podem ser mais eficientes e a superação de dilemas fiscais, (IFSL, 2003; HM Treasury, 2003, 2006).

No entanto, no Estado de MG, como no Brasil, parece que a falta de recursos pode ter sido o elemento decisivo para a implementação das PPPs. Não se busca uma melhor alocação de recursos, ou mesmo, o aumento da eficiência do gasto público, mas tão somente receitas adicionais para o financiamento das despesas públicas crescentes. $\mathrm{O}$ volume expressivo da despesa com pessoal sobre a receita de ICMS entre 1996 e 2016 (vide Figura 1) evidencia uma despreocupação com o aumento da eficiência do gasto pelo estado. 
Figura 1. Despesa de Pessoal sobre Receita de ICMS

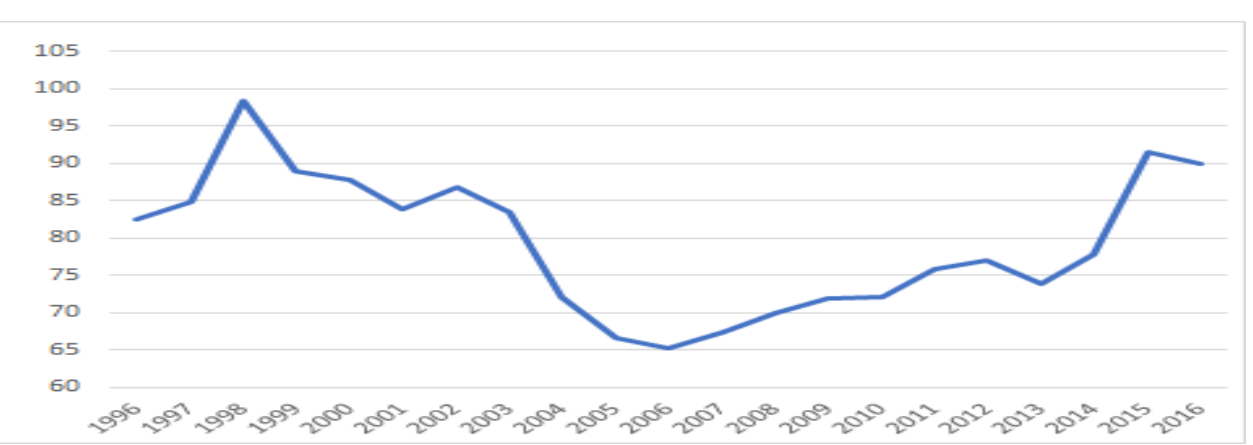

Fonte. Secretaria do Tesouro Nacional/Ministério da Economia.

Não é por outra razão que Monteiro (2006) chega a afirmar que o governo emprega PPPs com a expectativa de vir a ser avaliado pela provisão de melhorias nos serviços públicos. O agente público fornece bens públicos aos eleitores para obter votos.

Essa é justamente a proposição da teoria da escolha pública, que considera o agente público um maximizador de benefício próprio, ainda que em detrimento do Estado seu empregador, formulando políticas públicas de aumento da oferta de bens públicos e de salários de servidores para aumento de popularidade entre eleitores. Os resultados das ações dos formuladores de política pública são despesas e dívidas públicas crescentes.

\section{MÉTODOS}

Considerando o exposto por Vergara (2010), a metodologia empregada neste trabalho é exploratória quanto à finalidade. A pesquisa é exploratória na medida que apresenta as relações de causalidades dos eventos econômicos, e quais os efeitos resultantes da utilização dos recursos. Conforme Gil (2010) e Andrade (2000), procurouse apresentar os fatos, registrá-los, analisá-los, como esperado por Caws (1972).

Assim, o artigo descreve o comportamento da dívida do Estado de Minas Gerais no período 1996 a 2016 com o propósito de verificar se a despesa de pessoal comprometeu o crescimento da economia, transferindo o ônus do maior dispêndio com pessoal por intermédio da dívida pública para as gerações futuras. A crescente despesa com pessoal resultaria em aumento da dívida pública e imporia um fardo nas gerações futuras por meio do aumento de impostos e a consequente redução de suas rendas, o que nada mais é do que uma forma de ação da Equivalência Ricardiana, hipótese tratada por Jung (2018) para a economia brasileira e detalhado por Lara (2016).

Inicialmente, para o entendimento do comportamento da dívida e dos fatores que poderiam contribuir para explicá-lo, utilizou-se a pesquisa bibliográfica, que se caracteriza pelo contato com o que já foi escrito sobre o assunto em questão (Lakatos e Marconi, 2010), bem como a pesquisa da legislação afeta à matéria.

O método de abordagem da pesquisa é considerado misto, com uma discussão teórica, qualitativa e com a aplicação de econometria posto que "busca por meio da literatura existente a compreensão das especificidades de um fenômeno em termos de suas origens e sua razão de ser" (HAGUETTE, 1995, p. 63). O teor econométrico tem o fim de verificar se as variáveis despesa com pessoal e o serviço da dívida afetaram os níveis de dívida pública estadual por intermédio de relações lineares. 


\subsection{O Modelo}

Os dados foram coletados no site do Tesouro Nacional e no IBGE para os anos 1996 a 2016. A estimativa da dívida fundada do Estado como variável dependente e a despesa com pessoal e o serviço da dívida foi realizada a partir de uma equação:

$Y_{t}=\beta_{1}+\beta_{2} X_{t-1}+\beta_{3} Z_{t}$

Onde:

$\mathrm{Y}_{\mathrm{t}}=$ dívida fundada do estado no ano $\mathrm{t}$,

$\beta_{1}=$ ponto de intercepto ou termo constate informa o valor de $Y_{t}$ quando $\mathrm{Xt}$ e $\mathrm{Zt}$ são iguais a zero.

$\beta_{2}=$ coeficiente angular da regressão que estima o impacto da despesa com pessoal sobre a dívida; portanto, a sensibilidade da dívida em relação às variações da despesa com pessoal.

$\mathrm{X}_{\mathrm{t}}=$ despesa com pessoal no ano $\mathrm{t}-1$. Isto porque, a despesa com pessoal em $\mathrm{t}-1$ impacta a dívida no período $\mathrm{t}$.

$\beta_{3}=$ coeficiente angular da regressão que estima o impacto do serviço da dívida sobre a dívida; em outros termos, indica o efeito da variável explicativa sobre a dívida.

$\mathrm{Z}_{\mathrm{t}}=$ serviço da dívida do Estado no ano t, disponibilizado no site da STN.

Primeiramente, utilizando os dados coletados de dívida consolidada e receita com ICMS, serviço da dívida, despesa com pessoal dos anos de 1996 a 2016, organizou-se a Tabela 1, para melhor leitura e posterior análise, com o emprego da regressão.

Tabela 1. Dados por período utilizados na pesquisa

\begin{tabular}{|c|c|c|c|}
\hline período & Dívida/PIB & Desp Pessoal/ICMS & serv. Da dívida/PIB \\
\hline 1996 & $18.00 \%$ & $82.50 \%$ & $5.69 \%$ \\
\hline 1997 & $18.96 \%$ & $84.79 \%$ & $4.22 \%$ \\
\hline 1998 & $18.70 \%$ & $98.42 \%$ & $0.20 \%$ \\
\hline 1999 & $30.12 \%$ & $88.91 \%$ & $1.27 \%$ \\
\hline 2000 & $29.53 \%$ & $87.68 \%$ & $1.65 \%$ \\
\hline 2001 & $29.78 \%$ & $83.88 \%$ & $1.43 \%$ \\
\hline 2002 & $27.25 \%$ & $86.83 \%$ & $1.18 \%$ \\
\hline 2003 & $25.35 \%$ & $83.37 \%$ & $1.09 \%$ \\
\hline 2004 & $24.02 \%$ & $72.13 \%$ & $0.99 \%$ \\
\hline 2005 & $22.31 \%$ & $66.61 \%$ & $1.04 \%$ \\
\hline 2006 & $21.07 \%$ & $65.23 \%$ & $1.10 \%$ \\
\hline 2007 & $20.29 \%$ & $67.38 \%$ & $1.05 \%$ \\
\hline 2008 & $19.82 \%$ & $69.92 \%$ & $1.07 \%$ \\
\hline 2009 & $19.62 \%$ & $71.85 \%$ & $1.13 \%$ \\
\hline 2010 & $18.36 \%$ & $72.14 \%$ & $9.60 \%$ \\
\hline 2011 & $17.62 \%$ & $75.81 \%$ & $9.90 \%$ \\
\hline 2012 & $16.81 \%$ & $76.88 \%$ & $1.02 \%$ \\
\hline 2013 & $17.31 \%$ & $73.89 \%$ & $1.70 \%$ \\
\hline 2014 & $17.28 \%$ & $77.77 \%$ & $11.00 \%$ \\
\hline 2015 & $20.06 \%$ & $91.43 \%$ & $1.30 \%$ \\
\hline 2016 & $20.26 \%$ & $89.97 \%$ & $5.20 \%$ \\
\hline
\end{tabular}

Fonte. Secretaria do Tesouro Nacional(STN) do Ministério da Economia. 


\subsection{RESULTADOS}

A realização dos cálculos econométricos foi com o uso do pacote estatístico Eviews. De acordo com Brooks (2014) e Gujarati (2005), os estimadores de mínimos quadrados ordinários (MQO) obtidos são eficientes e não tendenciosos e confiáveis quando submetidos a testes comprovatórios.

Foram realizados testes de autocorrelação para verificar se o termo de erro em um período t está associado com o termo de erro no período $\mathrm{t}-1$. Caso fosse verificada autocorrelação dos erros, os parâmetros de MQO estimados seriam ainda não-viesados e consistentes, mas os erros padrões dos parâmetros estimados da regressão seriam viesados, levando a testes estatísticos incorretos e intervalos de confiança viesados. A evidência da presença de autocorrelação é dada pelo valor muito baixo da estatística Durbin-Watson.

Também foi realizado o teste White para verificar se os erros seriam heterocedásticos. Modelos com erros heterocedásticos não são mais os MELNT e os erros-padrão dos estimadores são superestimados e as estatística T e F são viesadas, o que compromete a validade dos testes.

As consequências de erros heterocedásticos são similares aos presentes na autocorrelação dos erros. Os coeficientes estimados ainda são não viesados, porém ineficientes, i.e., não são mais os melhores estimadores não viesados (MELNV), mesmo em amostras grandes, de modo que o desvio padrão estimado pode estar errado. Ter-seia, como consequências de usar MQO com heterocedasticidade obter, os intervalos de confiança e teste de hipóteses $t$ imprecisos em função do erro padrão e as inferências estarem incorretas. Neste suposto caso, o método de mínimos quadrados ordinários (MQO) não seria adequado. Ademais, $\mathrm{R}^{2}$ tende a valores maiores ao seu correto valor se a autocorrelação está presente, porém ignorada, desde que a autocorrelação levará a subestimação da variância do erro verdadeiro (para auto correlação positiva).

$\mathrm{O}$ teste $\mathrm{F}$ tem como hipótese nula de que todos os coeficientes são iguais a zero. Valores de prova abaixo de 5\%, ou valores menores, significam a rejeição da hipótese nula e, portanto, que o conjunto de coeficientes é distinto de zero. A rejeição da hipótese nula, com o teste $\mathrm{F}$, pode ser interpretado como a existência de correlação entre as variável explicativas e a dependente. $\mathrm{O}$ coeficiente de determinação, $\mathrm{R}^{2}$, é uma medida de qualidade do modelo estatístico, em que, o $\mathrm{R}^{2}$ varia entre 0 e 1 , indicando, em percentagem, o quanto as variáveis explicativas se relacionam com a dependente. Quanto maior o $\mathrm{R}^{2}$, mais as variáveis explicativas estão correlacionadas à dependente.

Assim, a importância das variáveis explicativas, despesa com pessoal e o serviço da dívida, foram testadas pelos testes $\mathrm{F}$ e $\mathrm{R}^{2}$. $\mathrm{O}$ exame dos testes permite assegurar a validade dos testes paramétricos e, portanto, que não rejeitemos os resultados dos parâmetros nem para os intervalos de confiança. Em outros termos, as variáveis explicativas podem explicar a variável dependente.

Os resultados (Vide Tabela 2) indicaram como valor estimado, para o ponto de intercepto, -0,00906 a um valor $\mathrm{p}=0,896$, o que faz com que se possa assumir que o ponto de intercepto seja igual a zero. O coeficiente $\beta$ para a variável $\mathrm{X}(-1)$, despesa com pessoal sobre ICMS defasada, foi de 0,298394, com $\mathrm{p}=0,0026$ (menor do que 0,05), podendo-se afirmar que $\mathrm{X}$ (despesa com pessoal) explica a variável dependente $\mathrm{Y}$, dívida sobre PIB. Contudo, o serviço da dívida não impactou a dívida. Apesar dos volumes crescentes da dívida, o serviço da dívida variou inversamente devido às sucessivas negociações perante o governo federal, o que permitiu menor pagamento de juros. Também a queda de juros contribuiu para a redução do montante do serviço da dívida. 
Assim, a dívida do Estado foi explicada pelos sucessivos aumentos da despesa com pessoal, que inclui desembolsos com ativos e inativos.

Tabela 2. Resumo dos resultados estatísticos

\begin{tabular}{ccccc}
\hline Variável & Coeficientes & Erro Padrão & Estatística-T & Prob. \\
\hline $\mathrm{C}$ & $-0,00906$ & 0,06829 & $-0,13270$ & 0,89600 \\
$\mathrm{X}(-1)$ & 0,29839 & 0,08478 & 3,51973 & 0,00260 \\
$\mathrm{Z}$ & $-0,38197$ & 0,28089 & $-1,35985$ & 0,19160 \\
\hline
\end{tabular}

Fonte. Elaboração própria, a partir dos dados calculados no E-views.

Os resultados da regressão estão apoiados no teste Jarque-Bera que tem como hipótese nula, a normalidade ver Brooks (2014) e são mostrados na Figura 2.

Figura 2. Resultado do teste Jarque-Bera

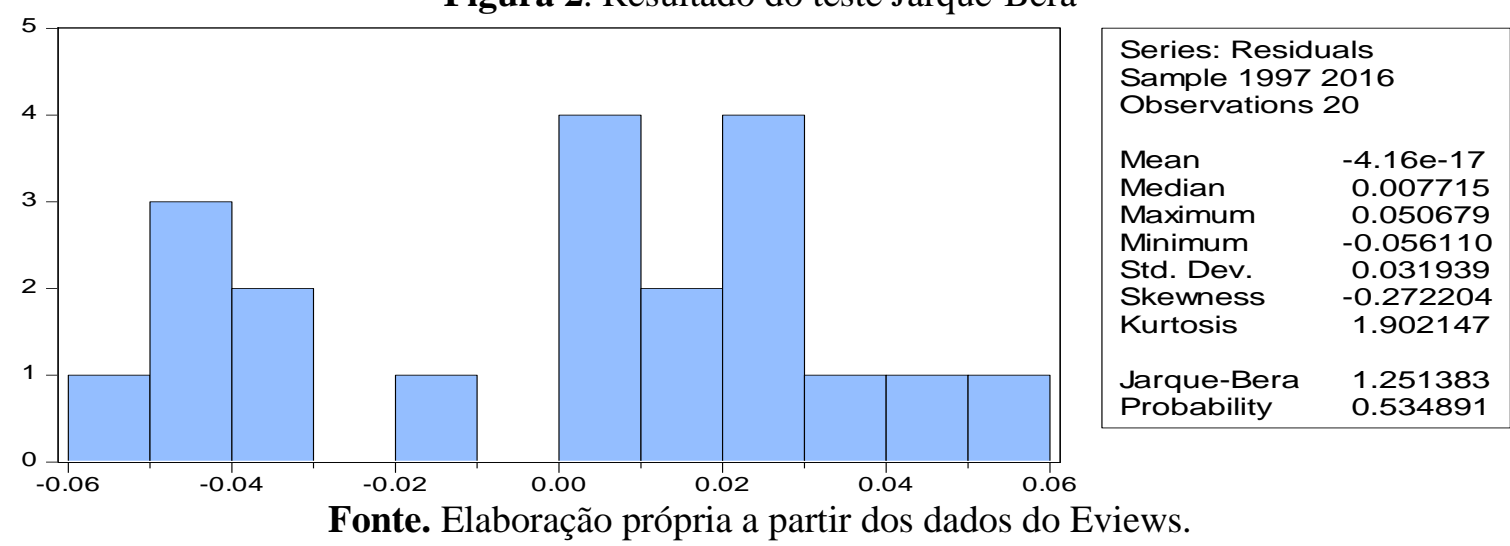

O teste Jarque-Bera encontrou o valor 1,251383, o que corresponde a um valor $\mathrm{p}$ de 0,53489 . Considerando que a hipótese nula do teste é que os resíduos são normalmente distribuídos e que o valor $\mathrm{p}$ de $0,53489>0,10$, aceita-se a normalidade da distribuição dos erros.

$\mathrm{O}$ valor $\mathrm{p}$ de 0,534891 , informado na Figura 2 , muito acima de $10 \%$, permite que não seja rejeitada a hipótese nula (H0), de distribuição normal. Ademais, os coeficientes de curtose e assimetria (que na distribuição normal são de 3 e 0 , respectivamente) apresentaram uma curtose abaixo de 4 e assimetria abaixo de 1, admissíveis para uma distribuição normal, como disposto em Gujarati (2005). Portanto, a assunção da normalidade dos erros tem amparo nos requisitos econométricos constante na literatura.

O teste white apresentou um valor p de 0,2644 , o que leva a aceitação de que os erros são homocedásticos. Acresce-se que não houve evidência de autocorrelação de qualquer ordem, como se depreende da interpretação do teste estatística de Q (L.Jung-Box) para os resíduos levados ao quadrado. Assim, trata-se de uma série sem correlação serial. Caso houvesse autocorrelação dos erros, o modelo deixaria de ser eficiente e os testes estatísticos deixam de ser válidos, contudo, continuaria não tendencioso e consistente.

O correlograma mostra a correlação amostral do erro inicial com valores baixos (iniciando com 0,237) e diminui gradualmente, alcançando na defasagem 4, o valor 0,08. Tal aspecto evidencia que os erros não estão autocorrelacionados, como a estatística Durbin-Watson (DW) já indicava. Sendo que a estatística DW realiza teste para verificar apenas autocorreção de ordem 1, a mais frequente em economia. Sendo assim, é possível afirmar que não houve violação da hipótese "ausência de correlação serial". A presença 
de "correlação serial" faria com que os coeficientes estimados, os $\beta_{\text {is }}$, deixassem de ser os mais eficientes e os testes estatísticos não poderiam ser considerados válidos.

Figura 3. Correlograma

Date:11/14/19 Time: 21:48

Sample: 19962016

Included observations: 20

\begin{tabular}{|c|c|c|c|c|c|c|c|c|}
\hline \multicolumn{2}{|c|}{ Autocorrelation } & \multicolumn{2}{|c|}{ Partial Correlation } & & $A C$ & PAC & Q-Stat & Prob \\
\hline$\square$ & 1 & $F$ & 1 & 1 & 0.237 & 0.237 & 1.3030 & 0.254 \\
\hline$\square$ & 1 & p & 1 & 2 & 0.119 & 0.067 & 1.6500 & 0.438 \\
\hline D & 1 & b & 1 & 3 & 0.087 & 0.048 & 1.8452 & 0.605 \\
\hline$\dot{0}$ & 1 & b & 1 & 4 & 0.080 & 0.045 & 2.0191 & 0.732 \\
\hline 1 प & 1 & 1 미 & 1 & & $-0.11 \ldots$ & $-0.15 \ldots$ & 2.3838 & 0.794 \\
\hline 1 व & 1 & 10 & 1 & & $-0.11 \ldots$ & $-0.08 \ldots$ & 2.8228 & 0.831 \\
\hline 1 व & 1 & 14 & 1 & & $-0.16 \ldots$ & $-0.11 \ldots$ & 3.7207 & 0.811 \\
\hline $1 \square$ & 1 & 1 미 & 1 & & $-0.24 \ldots$ & $-0.17 \ldots$ & 5.8919 & 0.659 \\
\hline $1 \square$ & 1 & 1 口 & I & & $-0.30 \ldots$ & $-0.19 \ldots$ & 9.5321 & 0.390 \\
\hline $1 \square$ & 1 & 14 & I & $\mid 1 \ldots$ & $-0.23 \ldots$ & $-0.13 \ldots$ & 12.042 & 0.282 \\
\hline 1 & 1 & i & 1 & $\mid 1 \ldots$ & $-0.04 \ldots$ & 0.068 & 12.141 & 0.353 \\
\hline b & 1 & $\square$ & 1 & $1 \ldots$ & 0.062 & 0.121 & 12.355 & 0.418 \\
\hline
\end{tabular}

Fonte. Elaboração do autor a partir do uso do Eviews.

Não foram encontradas evidências de heterocedasticidade nem de correlação serial. Relativamente ao teste $\mathrm{F}$ (conforme Tabela 3), o resultado do teste aponta um nível de significância a $5 \%$, na verdade até mesmo a $1 \%$, pois o $p=0,004175$. Assim, os coeficientes do modelo são diferentes de zero. A hipótese nula do teste $\mathrm{F}$ é que os coeficientes ( $\beta 1$, ponto de intercepto; $\beta 2$ coeficiente da reta de regressão que mede o impacto da despesa com pessoal sobre a dívida; $\beta 3$, coeficiente da regressão que mede o impacto do serviço da dívida sobre a dívida) conjuntamente são iguais a zero. Em outros termos, é rejeitada a hipótese nula de que "todos" coeficientes estimados pela regressão são simultaneamente iguais a zero. $O$ coeficiente de determinação, $R^{2}$, foi de 0,475095 (valor ajustado em 0,413341), vide Tabela 4, um valor expressivo, compatível com o teste $\mathrm{F}$, mostrando que as variáveis dependentes explicaram a dívida do estado.

Tabela 3. Resultados do Teste F.

\begin{tabular}{lr}
\hline F-statistic & 7,693406 \\
Prob (F-statistic) & 0,004175 \\
\hline \multicolumn{2}{l}{ Fonte. Resultados da Pesquisa }
\end{tabular}

Tabela 4. Resultados do Coeficiente de determinação.

\begin{tabular}{lr}
\hline R-squared & 0,475095 \\
Adjusted R-squared & 0,413341 \\
S.E. of regression & 0,033765 \\
Sum squated resid & 0,019381 \\
\hline \multicolumn{2}{l}{ Fonte. Resultados da Pesquisa }
\end{tabular}




\section{COMENTÁRIOS FINAIS}

A relação entre serviço da dívida do Estado de Minas Gerais e a dívida do Estado não apresentou uma relação estatística significativa, o que permite que se afirme que o pagamento de juros não foi responsável pelo incremento da dívida pública do Estado. $\mathrm{O}$ serviço da dívida pública estadual não cresceu porque o Estado conseguiu reduções nas taxas de juros em negociações com o Governo Federal, apesar dos volumes crescentes da dívida.

No entanto, foi encontrada uma relação de cerca de $30 \%$ entre o aumento das despesas com pessoal e o acréscimo da dívida pública do Estado de Minas Gerais, de acordo com os testes estatísticos. Considerando-se o resultado econométrico, observa-se que a despesa com pessoal foi um dos principais elementos que explicaram o crescimento da dívida no Estado.

O resultado estatístico encontrado tem respaldo na teoria da escola das escolhas públicas. Para os autores da escola das escolhas públicas, reivindicações corporativistas e eleição de políticos gastadores caminham juntas e resultam em aumentos da despesa com pessoal e no crescimento da dívida. A evolução das contas públicas do Estado revela que a política econômica está subjugada aos interesses da burocracia estatal que consome folgas fiscais por intermédio de aumento de despesa com pessoal e que, portanto, a política econômica não está orientada para o crescimento econômico.

Assim, um exame superficial das contas públicas de MG descreve um aparente paradoxo: de um lado, as tendências da expansão do gasto público; de outro, o emprego de PPPs para contração da despesa pública e busca do aumento de eficiência na gestão pública. No entanto, os gastos do Estado são onerados pela folha de pagamento e os ganhos fiscais com as PPPs são absorvidos pelo incremento da despesa pública, resultando numa dívida pública crescente.

A expansão dos gastos na previdência, nas despesas com pessoal e nas obrigações financeiras evidenciam que a questão fiscal não é facilmente equacionada. $\mathrm{O}$ Estado não vem seguindo uma rígida disciplina fiscal, pois sequer o caminho da prudência determinado pela LRF foi seguido, agravando a situação econômica. Como a política econômica vem gerando uma dívida crescente, pode-se afirmar que as despesas do Estado não estão voltadas para fomentar o crescimento econômico, mas sim para a realização de despesas de interesse de grupos de pressão. O esforço governamental está voltado aos itens que mais corroem as receitas públicas.

A aparente contradição se reforça ainda com o fato de que o percentual de limite de 5\% da Receita Corrente Líquida (RCL) estabelecido pela Lei ${ }^{\circ} 11.079 / 2004$ para as PPPs não é suficiente por si só para alavancar o crescimento e eventuais ganhos são perdidos com aumento de desembolsos em outros segmentos.

Uma outra constatação relevante é a de que a expansão da oferta de bens públicos por intermédio das PPPs encontra alguns obstáculos. Preocupa a formulação de Editais de PPPs, pois, se mal delineados, podem ser danosos aos cofres públicos e ao projeto de substituição da atividade pública pela privada.

Para que as PPPs estimulassem o investimento no Estado, seria necessário que a burocracia pública fosse eficiente, como preconizado por Weber (1994), uma organização com adequação dos meios aos objetivos desejados, a fim de alcançar a máxima eficiência. No entanto, a burocracia brasileira está inserida numa cultura em que há um baixo grau de institucionalização, em que tais problemas não podem ser resolvidos apenas com edição de leis nem sempre implementadas. Isso permite afirmar que o Estado não dispõe de um grau de institucionalização para fomentar o crescimento econômico. 
A adoção de práticas de contabilidade questionáveis pode ter o intuito de obter maior aceitação do governante, com o aumento de eleitores mal informados. A contabilidade criativa implementada no Estado não permitiu criar recursos para pagamento, por exemplo, do décimo-terceiro salário do funcionalismo e, mais recentemente, do próprio salário, muitas vezes realizado com atraso. Com a queda de arrecadação a partir de 2013, tornou-se impossível honrar os pagamentos da folha com pontualidade. Preocupa também que o montante da receita tributária esteja aquém do seu potencial quando se compara aos outros três estados ricos.

O elevado percentual de despesa pessoal sobre a receita de ICMS, a adoção de práticas de contabilidade criativa e o montante da receita tributária aquém do seu potencial são características preconizadas na teoria das Escolhas Públicas como iniciativas políticas voltadas para a reeleição, em detrimento da busca de eficiência estatal.

Finalmente, a análise das contas do Estado mostra que o crescimento da despesa com pessoal e da dívida pública elimina qualquer ganho fiscal com as PPPs e outras folgas fiscais. Sendo assim, a implementação das PPPs teve o objetivo apenas de gerar caixa para que o Estado possa prosseguir com a política de expansão de gastos, em especial de despesa com pessoal. Sugere-se para estudos futuros, a elaboração de estudos econométricos das PPPs como promotora de crescimento em outros estados brasileiros, o que possibilitaria uma comparação interestadual.

\section{REFERENCIAS}

ALESINA, A. et al. Political instability and economic growth. Journal of Economic growth, v. 1, n. 2, p. 189-211, 1996.

ANDRADE, M. M. de. Como Preparar Trabalhos Para Cursos de Pós-graduação: Noções Práticas. Editora Atlas SA, 2000.

ARRAES, R. A.; TELES, Vladimir Kühl. Endogeneidade versus exogeneidade do crescimento econômico: uma análise comparativa entre Nordeste, Brasil e países selecionados. Revista Econômica do Nordeste, v. 31, p. 754-776, 2000.

BORCHERDING, T. E.; BUSH, W.C.; SPANN, R.M. Budgets and bureaucrats: The sources of government growth, 211-228. Durham: Duke University Press, 1977.

BOUBAKRI, N.; COSSET, J. C.; SAFFAR, W. Political connections of newly privatized firms. Journal of Corporate Finance, 14(5), 654-673, 2008.

BRANCO, P. G. G.; COELHO, I. M.; MENDES, G. F. Curso de Direito Constitucional. rev. e atual. São Paulo: Saraiva, v. 20, n. 2, 2008.

BRASIL. Exposição de Motivos Interministerial (EMI) no 355/2003/MP/MF, disponível no site: http://www.planalto.gov.br/ccivil_03/Projetos/EXPMOTIV/EMI/2003/EMI355MPMF-2003.htm, 2003.

BRASIL. Lei n. ${ }^{\circ} 11.079$ de 30 de dezembro de 2004. Institui normas gerais para licitação e contratação de parceria público-privada no âmbito da administração pública. Brasília: Presidência da República, 2004.

BREY, N. K. et al. Conexões políticas em estruturas de propriedade: o governo como acionista em uma análise descritiva. Revista de Administração Mackenzie (Mackenzie Management Review), v. 15, n. 1, 2013. 
BROOKS, C. Introductory econometrics for finance. Cambridge university press, 2014.

BUCHANAN, J. M. The Samaritan's Dilemma. In: E. Phelps, ed. 1975. Altruism, Morality and Economic Theory. New York: Russell Sage, p. 71-85, 1972

BUCHANAN, J. M.; CONGLETON, R. D. Politics by principle, not interest: Toward nondiscriminatory democracy. Cambridge University Press, Cambridge; quoted according to Volume 11 of the Collected Works of James M. Buchanan, Liberty Fund, Indianapolis, 1998.

BUCHAnAN, J. M.. The Public Finances, Illinois: Richard D. Irwin, INC, 1967.

CARDOSO F., CORREA D.; LIMA G. T. Mudança estrutural, desenvolvimento institucional e crescimento econômico sustentado: um comentário sobre a experiência irlandesa. Rev. Econ. Politica. vol.29 no.1 São Paulo Jan./Mar. 2009.

CAWS, P. Research methodology in Accounting-Scholars Books, 1972.

COSSALTER, P. A. Private Finance Initiative. Revista de direito público da economia, 2004.

CRUZ, V. L. P. et al. Transparência da gestão executiva municipal: um estudo dos Portais eletrônicos como promotores da accountability. 2017.

DIAS, O. C. Parcerias público-privadas como instrumento de implementação de políticas públicas. 2014.

DI PRIETO, M. S. Z. Direito Administrativo, Editora Atlas, 20ª edição, 2005.

FRIEDMAN, M.; FRIEDMAN, R. D. Capitalismo e liberdade. Editora Artenova, 1977.

GIL, A. C. Como Elaborar Projetos de Pesquisa. 5. a ed. São Paulo, Atlas, 2010.

GUJARATI, D. N. Basic econometrics. Tata McGraw-Hill Education, 2005.

HAGUETTE, T. M. Metodologias qualitativas na sociologia. 4.ed. Petrópolis:Vozes, 1995.

TREASURY, H. M. PFI: Meeting the Investment Challenge (London). 2003. TREASURY, H. M. PFI: strengthening long-term partnerships. Crown, London, 2006.

IFSL - INTERNATIONAL FINANCIAL SERVICES. Public private partnerships: UK expertise for international markets. London, 2003.

INTERNATIONAL MONETARY FUND (IMF). Public Private Partnership. Fiscal Affairs Department,. Disponível em: <www.imf.org/external/np/fad/2004/pifp/eng/031204.htm>. 2004, Acesso em: 3 jan. 2019.

JUNG, R. O. Hipótese da equivalência ricardiana: evidências para o Brasil (2000-2017). 2018 .

LANDAU D. L., (1985) "Government expenditure and economic growth in the developed countries: 1952-1976. Public Choice 47: 459-477.

LAKATOS, E. M; MARCONI, M. de A. Fundamentos da metodologia científica. In: Fundamentos da metodologia científica. Altas, 2010. 
LARA, L. P. de. Dívida pública e equivalência ricardiana: histórico, contexto e problemas. 2016.

MARLOW, M. L.; ORZECHOWSKI, W. Public sector unions and public spending. Public Choice 89: 1-16, 1996.

MERTON, R. K. Estrutura burocrática e personalidade. Campos, Edmundo. Sociologia da burocracia, v. 4, p. 107-124, 1978.

MONTEIRO, J. V. A conjuntura das escolhas públicas. Revista de administração pública, v. 40, n. 5, p. 945-958, 2006.

MONTEIRO, J. V. The dark side of public choice. Revista de Administração Pública, v. 41, n. 3, p. 585, 2007.

MORAES, A. de. Reforma Administrativa: Emenda Constitucional no 19/98. 3. ed., São Paulo : Atlas, p. 30, 1999.

NAZARETH, M. S.; LÍRIO, V. S. Federalismo fiscal de segunda geração: fundamentos teóricos e proposição política. Perspectiva Econômica, v. 12, n. 1, p. 16-28, 2016.

NUNES, R. da C.; NUNES, S. P. P. Revenue sharing: a problem of federalism in Brazil. Brazilian Journal of Political Economy, 20(4), 137-155, 2000.

PASIN, J. A. B.; BORGES, L. F. X. A nova definição de parceria público-privada e sua aplicabilidade na gestão de infra-estrutura pública. Banco Nacional de Desenvolvimento Econômico e Social (BNDES.), 2003.

PISSARIDES, C. A. British government popularity and economic performance. The Economic Journal, v. 90, n. 359, p. 569-581, 1980.

PRZEWORSKY, A. Nota sobre o Estado e o Mercado, Revista de Economia Política, 16:115-120, 1996.

ROMP, W.; DE HAAN, J. Public capital and economic growth: A critical survey. Perspektiven der Wirtschaftspolitik, v. 8, n. S1, p. 6-52, 2007.

ROUBINI, N. High public debt: The Italian experience: A review essay. Journal of Monetary Economics, v. 24, n. 3, p. 471-478, 1989.

SARMENTO, J. M.; RENNEBOOG, L. Anatomia das Parcerias Público Privadas: A sua criação, financiamento e renegociações. Econometrica, v. 67, p. 741-81, 2017.

SILVA, E. B. da. Práticas de contabilidade criativa nos estados brasileiros: influências dos ciclos eleitorais, 2018.

SHAPIRO, C.; WILLIG R.D. Economic rationales for the escope of privatization. Princeton University, 1990.

SOUYRI, P. Crises e Estagnação do Capitalismo: 1919-1939. In: - Compreende les idées dee XXe siècle. Paris, Marabout Université, 1977.

TULLOCK, G. The Vote Motive (2. rev. ed.), Peter Kurrild-Klitgaard, ed., IEA Hobart Paperback (No. 33). London: Institute of Economic Affairs.2006

VERGARA, S. C. Projetos e Relatórios de Pesquisa em Administração Editora Atlas S. A São Paulo, p. 43, 2010. 
WALD, A. A infra-estrutura, as PPPS e a arbitragem. Revista de Direito Público. Editora IOB, 2005.

WEBER, M. Economia e sociedade: fundamentos da sociologia compreensiva. Tradução de Regis Barbosa e Karen Elsabe Barbosa. Brasília: Ed. da UnB, 1994. 